\title{
IMPACT OF CELLULAR MICROENVIRONMENT AND MECHANICAL PERTURBATION ON CALCIUM SIGNALLING IN MENISCUS FIBROCHONDROCYTES
}

\author{
W.M. Han ${ }^{1}$, S-J. Heo ${ }^{1,2}$, T.P. Driscoll ${ }^{1,2}$, M.E. Boggs ${ }^{3}$, R.L. Duncan ${ }^{3,4}$, R.L. Mauck ${ }^{1,2}$ and D.M. Elliott ${ }^{4} *$ \\ ${ }^{1}$ Department of Bioengineering, University of Pennsylvania, Philadelphia, PA, USA \\ ${ }^{2}$ Department of Orthopaedic Surgery, Perelman School of Medicine, University of Pennsylvania, Philadelphia, \\ PA, USA \\ ${ }^{3}$ Department of Biological Sciences, University of Delaware, Newark, DE, USA \\ ${ }^{4}$ Department of Biomedical Engineering, University of Delaware, Newark, DE, USA
}

\begin{abstract}
Mechanical signals regulate a multitude of cell functions and ultimately govern fibrous tissue growth, maintenance and repair. Such mechanotransduction processes often involve modulation of intracellular calcium concentration $\left(\left[\mathrm{Ca}^{2+}\right]_{\mathrm{i}}\right)$. However, most studies interrogate these responses in cells in simplified culture systems, thereby removing potentially important inputs from the native extracellular microenvironment. The objective of this study was to test the hypothesis that the intracellular calcium response of meniscus fibrochondrocytes (MFCs) is dependent on both the microenvironmental context in which this perturbation is applied and on the tensile deformation. Using a custom micro-mechanical tester mounted on a confocal microscope, intracellular calcium activity in MFCs in response to incremental tissue strains $(0,3,6$ and $9 \%)$ was monitored in situ (i.e., in the native tissues) on MFC-seeded aligned scaffolds and MFC-seeded silicone membranes. The $\left[\mathrm{Ca}^{2+}\right]_{\mathrm{i}}$ regulation by MFCs within the native meniscus tissue microenvironment was considerably different from $\left[\mathrm{Ca}^{2+}\right]_{\mathrm{i}}$ regulation by MFCs on either aligned nanofibrous scaffolds or flat silicone membranes. Additionally, increasing levels of tensile deformation resulted in a greater number of responding cells, both in situ and in vitro, while having no effects on temporal characteristics of $\left[\mathrm{Ca}^{2+}\right]_{i}$ signalling. Collectively, these findings have significant implications for mechanobiology of load-bearing fibrous tissues and their responses to injury and degeneration. In addition, from a tissue engineering perspective, the findings establish cellular benchmarks for maturing engineered constructs, where native tissue-like calcium mechano-regulation may be an important outcome parameter to achieve mechanical functionality comparable to native tissue.
\end{abstract}

Keywords: Meniscus, fibrochondrocytes, microenvironment, tensile strain, intracellular calcium, oscillation, aligned scaffold, silicone membrane, mechanotransduction, fibrous tissues.

*Address for correspondence:

Dawn M. Elliott

Biomedical Engineering

University of Delaware

125 E. Delaware Ave.

Newark, DE 19716, USA

Telephone Number: 1-302-831-1295

E-mail: delliott@udel.edu

\section{Introduction}

In load-bearing tissues, mechanical signals regulate a diverse array of cellular functions, including viability, proliferation and metabolism (Killian et al., 2012; Mammoto et al., 2012). Many early mechanotransductive events involve the regulation of intracellular calcium concentrations $\left(\left[\mathrm{Ca}^{2+}\right]_{\mathrm{i}}\right)$, where $\mathrm{Ca}^{2+}$ can serve as a ubiquitous secondary messenger that activates downstream signalling pathways. For instance, various modes of mechanical perturbation, including fluid shear (Degala et al., 2011; Jing et al., 2013; Lu et al., 2012), hydrostatic pressure (Mizuno, 2005), osmotic stress (Pritchard et al., 2002; Pritchard and Guilak, 2004), and uniaxial compression (Campbell et al., 2008; Fitzgerald et al., 2004; Lee and Bader, 1997; Pingguan-Murphy et al., 2005; Pingguan-Murphy et al., 2006; Roberts et al., 2001; Tanaka et al., 2005) applied ex vivo to primary cells (i.e. chondrocytes, annulus fibrosus cells, osteocytes, osteoblasts, mesenchymal stem cells) leads to rapid increases $\left[\mathrm{Ca}^{2+}\right]_{\mathrm{i}}$ and can subsequently alter gene transcription and regulate protein synthesis (Chen et al., 2000; Chen et al., 2003; Fitzgerald et al., 2004; Lee and Bader, 1997; Tanaka et al., 2005). In addition, a growing body of evidence suggests that cells from these tissues can regulate the temporal characteristics of $\left[\mathrm{Ca}^{2+}\right]_{\mathrm{i}}$ oscillations that are evoked by mechanical stimulation to direct diverse and versatile cell functions (Berridge et al., 2003; Ishihara et al., 2012; Jing et al., 2013; Lu et al., 2012; PingguanMurphy et al., 2005; Pingguan-Murphy et al., 2006).

The knee meniscus is a load-bearing tissue in the knee that is sparsely populated with meniscal fibrochondrocytes (MFCs). While the meniscus and the cells within clearly respond to mechanical perturbation, there is currently limited information available on $\left[\mathrm{Ca}^{2+}\right]_{\mathrm{i}}$ temporal characteristics in response to mechanical perturbation in physiologically relevant microenvironmental contexts. Indeed, most studies to date evaluating mechanicallyinduced $\left[\mathrm{Ca}^{2+}\right]_{\mathrm{i}}$ signalling in a range of musculoskeletal cell types (e.g. chondrocytes, tenocytes, annulus fibrosus cells, osteoblasts, osteoclasts, myofibroblasts and mesenchymal stem cells) have utilised either isolated cells seeded on flat substrates (Arnoczky et al., 2002a; Chen et al., 2000; Godbout et al., 2013; Hutcheson et al., 2012; Jing et al., 2013; Kim et al., 2009; Lu et al., 2012; Mizuno, 2005; Pritchard et al., 2002) or cells encapsulated in soft gels, such as agarose (Elfervig et al., 2001; Pingguan-Murphy et al., 2005; Pingguan-Murphy et al., 2006; Roberts et al., 
2001; Wilson et al., 2009) and alginate (Campbell et al., 2008; Degala et al., 2011). While these simplified systems are valuable for understanding specific $\mathrm{Ca}^{2+}$ mediated mechanobiological pathways, these studies do not consider the role of cell matrix interactions in the transduction of physiologically-relevant mechanical signals. For instance, the average $\left[\mathrm{Ca}^{2+}\right]_{i}$ oscillation duration of chondrocytes in intact cartilage is shorter than that of chondrocytes cultured in monolayer or embedded in agarose constructs (Han et al., 2012), suggesting that the downstream cellular activities may be influenced by the cellular microenvironment. Therefore, an investigation comparing $\left[\mathrm{Ca}^{2+}\right]_{\mathrm{i}}$ oscillation profiles arising from mechanical perturbation in situ (in the native tissue) and in commonly used in vitro settings using the same experimental protocol is imperative in order to elucidate physiologically-relevant $\left[\mathrm{Ca}^{2+}\right]_{\mathrm{i}}$ signalling in tissues of both healthy and diseased states.

A further complication in the elucidation of cellular response as a function of microenvironment is the complex nature of the extracellular matrix (ECM) itself. For example, when fibre-reinforced tissues, such as tendon, meniscus, and annulus fibrosus, are subjected to tensile stretch, local matrix strain, and therefore cell strain, is significantly attenuated compared to tissue-level strain (Arnoczky et al., 2002b; Cheng and Screen, 2007; Han et al., 2013; Screen et al., 2004; Szczesny and Elliott, 2014; Upton et al., 2008). This phenomenon is attributed to several factors, including collagen fibre sliding (Bruehlmann et al., 2004b; Cheng and Screen, 2007; Duncan et al., 2014; Screen et al., 2004; Szczesny and Elliott, 2014), fibre rotation (Guerin and Elliott, 2006; Lake et al., 2009), and the presence of structural inhomogeneity within native tissues (Han et al., 2013; Melrose et al., 2001; Plaas et al., 2011; Sun et al., 2012; Vanderploeg et al., 2012; Wang et al., 2012). On the other hand, strain transfer in biomaterial substrates that lack these microstructural mechanisms and inhomogeneity is more direct (Han et al., 2013; Stella et al., 2008). While this suggests that cells within native tissues do not experience the same magnitude of strain as the entire tissue, how in situ local matrix and cell strains regulate $\mathrm{Ca}^{2+}$ signalling remains to be established.

The objective of this study was to determine if the $\left[\mathrm{Ca}^{2+}\right]_{\mathrm{i}}$ response in MFCs is dependent on cellular microenvironment and tensile deformation. To test this hypothesis, native meniscus tissue, MFC-seeded aligned nanofibrous scaffolds, and MFC-seeded silicone membranes were subjected to uniaxial tension while simultaneously monitoring $\left[\mathrm{Ca}^{2+}\right]_{i}$ using a confocal microscope. The outcomes of the current study identify clear differences in cell signalling between the in situ and in vitro environments, which may have significant implications for mechanobiology of musculoskeletal fibrous tissues that are prone to injury and degeneration. Moreover, the outcomes also impact tissue engineering by providing benchmarks of mechano-responsivity for maturing engineered constructs.

\section{Materials and Methods}

\section{Native tissue sample preparation}

Bovine menisci were obtained from juvenile animals within $12 \mathrm{~h}$ post-mortem. Isolated menisci were maintained in culture medium (Dulbecco's Modified Eagle Medium, DMEM, with $100 \mathrm{U} / \mathrm{mL}$ penicillin and $100 \mu \mathrm{g} / \mathrm{mL}$ streptomycin; Life Technologies, Grand Island, NY, USA) for no longer than $3 \mathrm{~h}$ before testing. Circumferentially oriented tissue samples were harvested from the outer region of the menisci. Harvested samples were cut to 12.0 x 3.0 x 0.3-0.8 mm (length $\mathrm{x}$ width $\mathrm{x}$ thickness) using a scalpel (Han et al., 2013).

\section{Cell isolation and expansion}

MFCs were isolated from the outer region of the medial and lateral menisci of juvenile bovine knees (Mauck et al., 2007). Briefly, outer menisci were harvested, and diced into 2-3 mm pieces. Diced meniscal pieces were plated in $15 \mathrm{~cm}$ tissue culture dishes with $30 \mathrm{~mL}$ of basal growth medium consisting of high-glucose (HG) DMEM containing $100 \mathrm{U} /$ $\mathrm{mL}$ penicillin and $100 \mu \mathrm{g} / \mathrm{mL}$ streptomycin/fungizone (1X PSF) and $10 \%$ foetal bovine serum (FBS). After 2 weeks, MFCs that had emerged from the meniscus pieces were re-plated and expanded through passage 2. Medium was changed every $3 \mathrm{~d}$.

\section{Aligned nanofibrous scaffold and silicone membrane preparation}

Aligned nanofibrous scaffolds and silicone membrane were used as deformable cell substrates. Poly( $\varepsilon$-caprolactone) (PCL, $80 \mathrm{kDa}$, Shenzhen Bright China Industrial Co. Ltd., Shenzhen, China) aligned nanofibrous scaffolds were fabricated by electrospinning (Baker and Mauck, 2007; Heo et al., 2011). Briefly, a PCL solution (14.3\% wt/ vol in 1:1 tetrahydrofuran and N,N-dimethylformamide) was extruded through an $18 \mathrm{G}$ stainless steel spinneret at a rate of $2.5 \mathrm{~mL} / \mathrm{h}$ towards a grounded aluminium mandrel rotating with linear velocity $10 \mathrm{~m} / \mathrm{s}$. The spinneret was charged to create a voltage gradient of $1 \mathrm{kV} / \mathrm{cm}$ relative to the grounded collector (ES30P-5W; Gamma High Voltage Research Inc., Ormand Beach, FL, USA). Silicone membrane was purchased from McMaster-Carr (87315K62; McMaster-Carr, Robbinsville, NJ, USA). Scaffolds $\left(5 \times 60 \times \sim 0.7 \mathrm{~mm}^{3}\right)$ and silicone membranes ( 5 x $60 \times \sim 0.3 \mathrm{~mm}^{3}$ ) were sterilised and rehydrated by incubating in decreasing concentrations of ethanol (100, $70,50,30$ and $0 \% ; 30 \mathrm{~min} / \mathrm{step}$ ) followed by incubation in $20 \mu \mathrm{g} / \mathrm{mL}$ fibronectin in phosphate buffered saline (PBS) for $12 \mathrm{~h}$ before seeding cells. Isolated MFCs $(50,000$ cells per scaffold or silicone membrane) were seeded onto the scaffolds or silicone membrane, and cultured for $2 \mathrm{~d}$ in chemically defined medium (Heo et al., 2011). PCL nanofibres average $\sim 500 \mathrm{~nm}$ diameter, providing numerous interactions for adherent cells and an instructional template for cell alignment, as established in our previous work (Baker et al., 2008; Baker et al., 2009a; Baker et al., 2009b; Baker et al., 2012; Heo et al., 2011; Mauck et al., 2009; Nathan et al., 2011). 

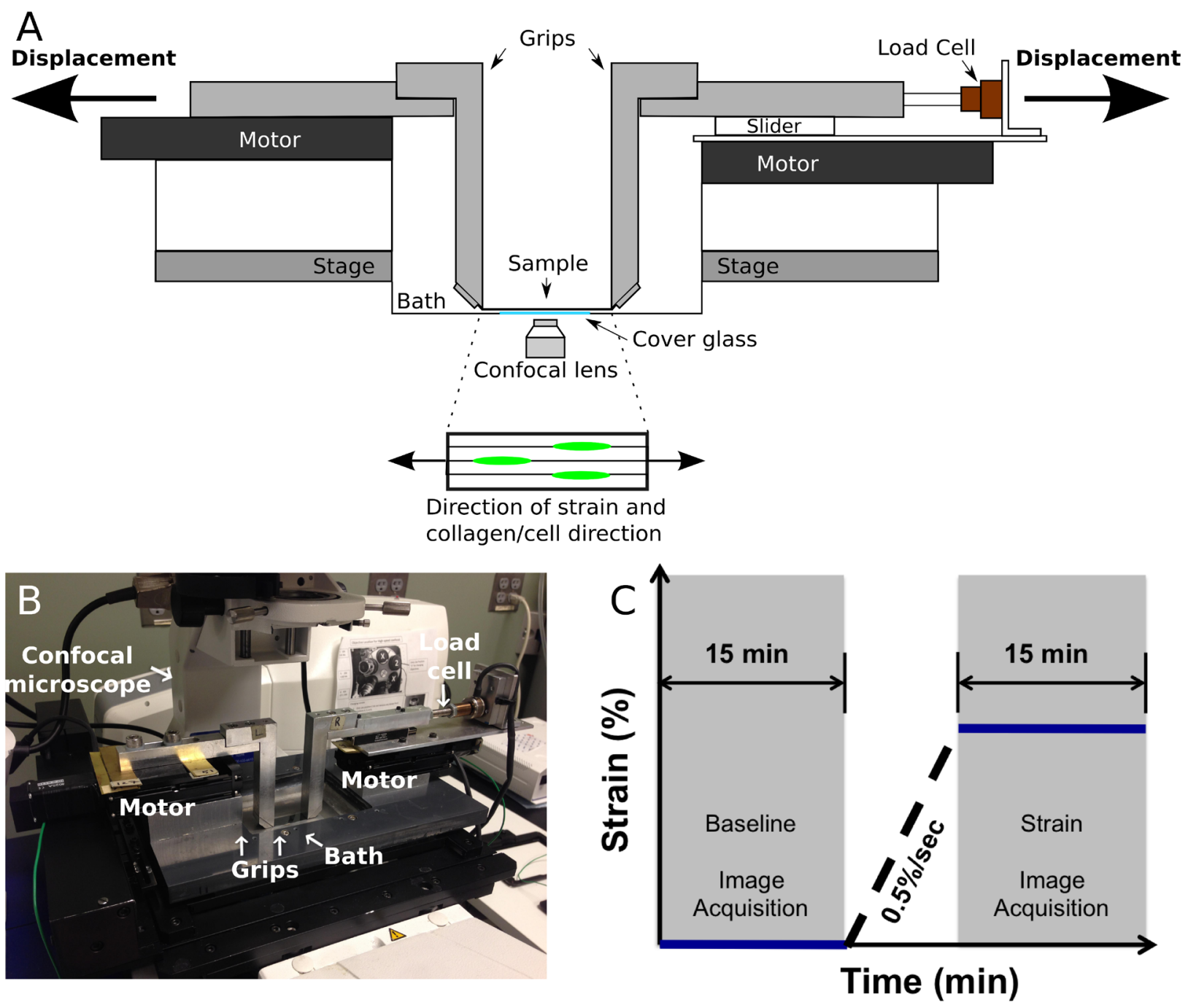

Fig. 1. (A) Diagram of the custom micromechanical test device. (B) Experimental setup of the custom micromechanical test device mounted on an inverted confocal microscope system. (C) Uniaxial strain application and confocal imaging protocol. A baseline time series of confocal images was acquired for $15 \mathrm{~min}$ (baseline), after which strain was applied at $0.5 \% / \mathrm{s}$, followed directly by another time series of confocal images acquired for an additional 15 min (strain).

\section{Custom micromechanical testing device}

A custom micromechanical test device mounted on the stage of a high-speed inverted confocal microscope system (LSM 5 LIVE; Carl Zeiss, Jena, Germany) was used to apply tensile deformation to samples (Han et al., 2013). Briefly, the device consisted of a $10 \mathrm{~N}$ load-cell (Honeywell, Columbus, OH, USA), two linear stepper motors (Zaber LSM025A-MC06; Zaber, Vancouver, Canada), and grips that extend from each motor into the sample bath (Fig 1A and B). This system permits gripping samples immediately above a cover glass to enable confocal imaging in an inverted configuration. A custom LabView (National Instruments, Austin, TX, USA) program was used to control the device.

\section{Uniaxial strain application and confocal imaging}

Prior to testing, cells were loaded with the fluorescent calcium indicator, Cal-520 ${ }^{\mathrm{TM}}$ AM $(15 \mu \mathrm{M}$, AAT Bioquest, Sunnyvale, CA, USA) and Hoechst 33422 (Life
Technologies, Carlsbad, CA, USA) in Hank's balanced salt solution (HBSS) (with $\mathrm{CaCl}_{2}, \mathrm{MgCl}_{2}$, and no phenol red; Life Technologies) for $1 \mathrm{~h}$ at $37{ }^{\circ} \mathrm{C}$ to visualise $\left[\mathrm{Ca}^{2+}\right]_{\mathrm{i}}$ levels and cell nuclei, respectively. Nuclear staining was used to count the total number of cells present in the field-of-view. Subsequently, samples were washed in HBSS to remove residual dye.

Samples were placed into the micromechanical test device mounted on the confocal microscope and kept submerged in an HBSS bath at room temperature throughout testing. Samples were preloaded to $30 \mathrm{mN}$ to remove slack and allowed to equilibrate for $15 \mathrm{~min}$. Preliminary experiments revealed that application of the $30 \mathrm{mN}$ preload resulted in less than $0.05 \%$ tissue-level strain. After preload, time-series images of baseline $\left[\mathrm{Ca}^{2+}\right]_{\mathrm{i}}$ responses were recorded every $4 \mathrm{~s}$ for $15 \mathrm{~min}$ $(0.25 \mathrm{~Hz}$ scanning frequency; baseline) using a $10 \mathrm{x}$ water-immersion lens (field-of-view: 900 x $900 \mu^{2}$ ). Grip-to-grip strain of 0, 3, 6 and $9 \%$ for the native tissue 


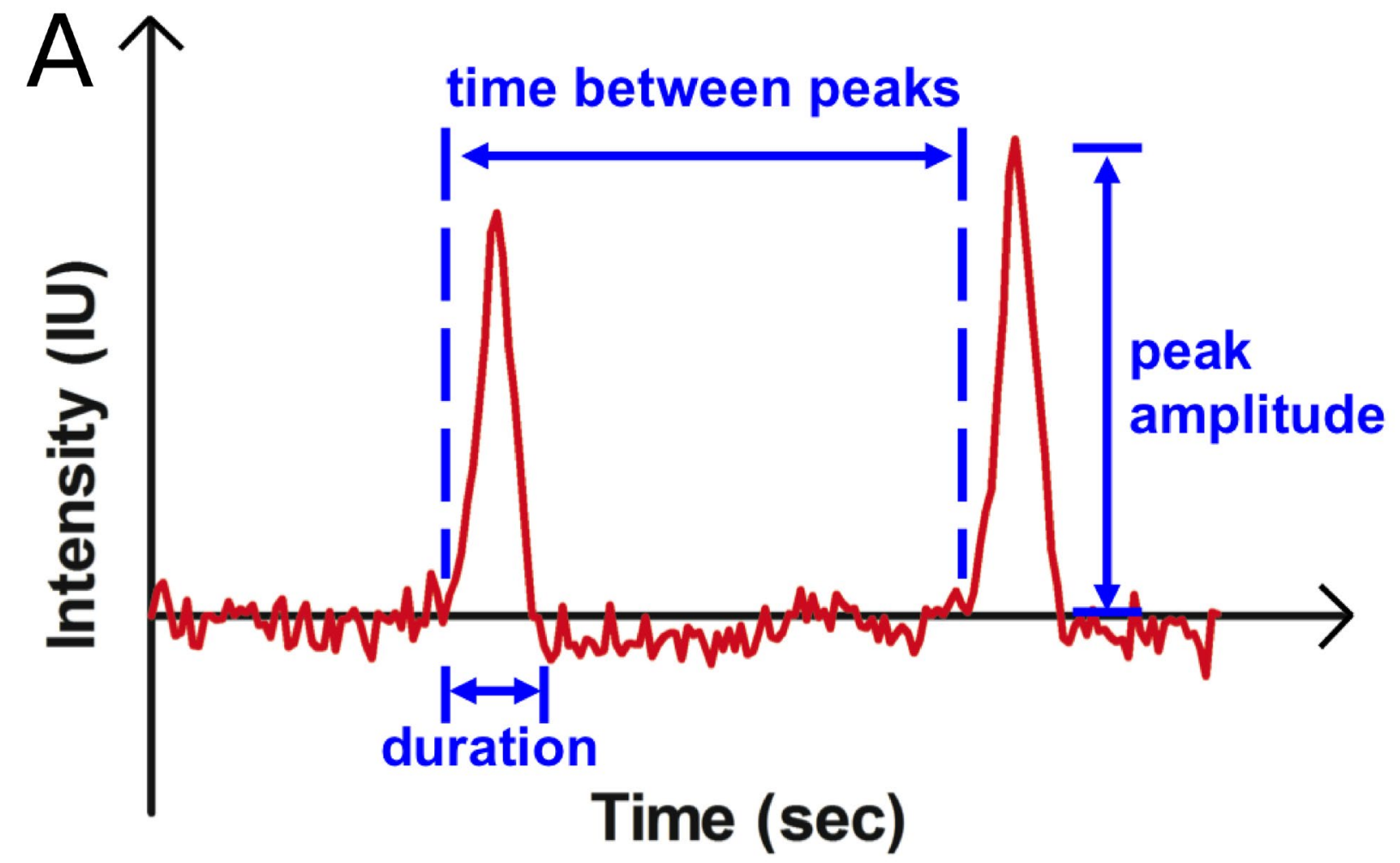

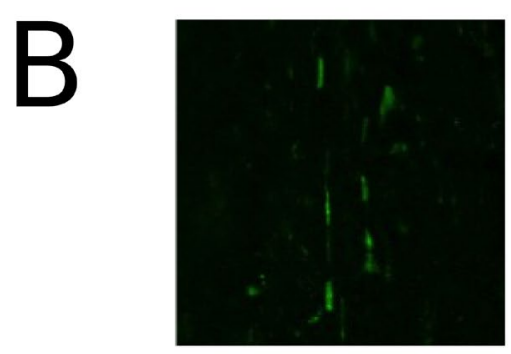

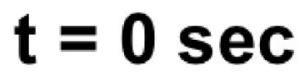

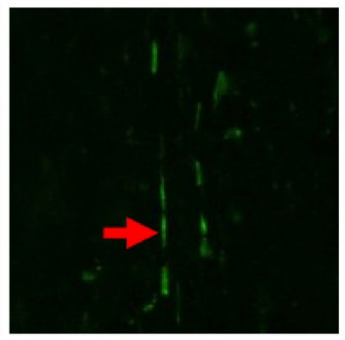

236

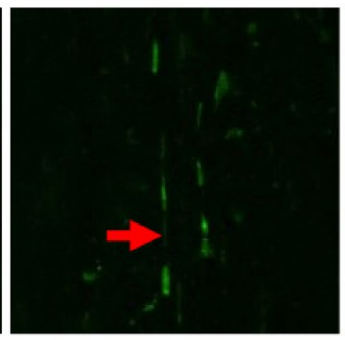

264

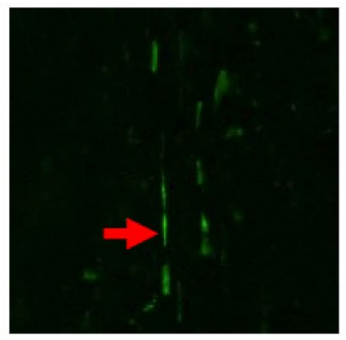

584

Fig. 2. (A) A representative $\left[\mathrm{Ca}^{2+}\right]_{\mathrm{i}}$ oscillation curve for MFCs in the native meniscus. $\left[\mathrm{Ca}^{2+}\right]_{\mathrm{i}}$ oscillation characteristics including peak amplitude, duration, time between peaks, and number of peaks were quantified. (B) An MFC in the native meniscus indicated by a red arrow exhibited $\left[\mathrm{Ca}^{2+}\right]_{i}$ oscillations as a function of time.

group and $0,1.5,3,6$ and $9 \%$ for aligned scaffold and silicone membrane groups was then applied at $0.05 \% / \mathrm{s}$ ( $n=4$ samples per strain group), and time-series images of $\left[\mathrm{Ca}^{2+}\right]_{\mathrm{i}}$ response in each strain group were acquired for an additional $15 \mathrm{~min}$ (Fig. 1C).

\section{Data analysis}

A custom MATLAB (The Mathworks Inc., Natick, MA, USA) program was used to analyse $\left[\mathrm{Ca}^{2+}\right]_{\mathrm{i}}$ oscillations (oscillation peak amplitude, duration, time between peaks, and number of peaks; Fig. 2A). Briefly, for each set of images, the program enables a user to draw a polygon to specify a background region and a cell of interest. Mean background intensity is subtracted from the mean intensity of a responding cell for normalisation. Subsequently, the program outputs $\left[\mathrm{Ca}^{2+}\right]_{i}$ oscillation curves [Intensity (IU) vs. time (seconds)], and determines oscillation peak amplitude, duration, time between peaks, and number of peaks. $\left[\mathrm{Ca}^{2+}\right]_{\mathrm{i}}$ oscillations $(n=50)$ arising from at least 30 responding cells were analysed for each strain group. ImageJ (National Institutes of Health, Bethesda, MD, USA) was used to determine the percentage of responding cells ( $n=4$ per strain group), cell area $\left(\mu \mathrm{m}^{2}\right)$, cell aspect ratio, and cell circularity ( $n=30$ for cell shape parameters).

A one-way ANOVA with Tukey's post-hoc was used to test for significant differences compared to baseline (factor: microenvironment; i.e. tissue and substrate), change in the percentage of responding cells data (factor: strain), and cell shape parameters (factor: microenvironment). A two-way ANOVA with Bonferroni post-hoc (factors: strain and microenvironment) was used to test for significance between groups for all other data. Significance was set at $p<0.05$. All data are presented as mean \pm standard error, unless indicated otherwise. 

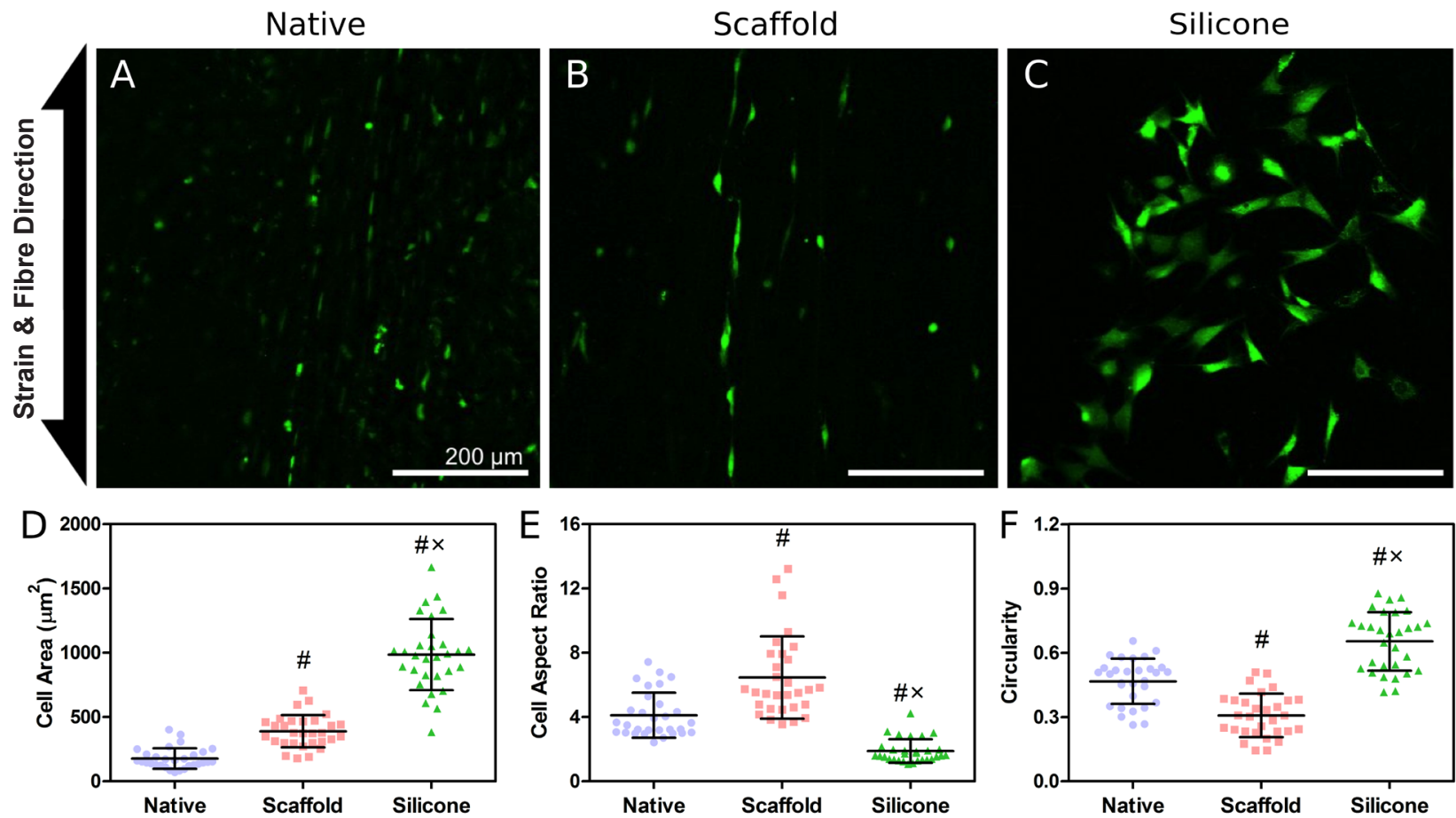

Fig. 3. Representative confocal images (10x) of (A) native meniscus, (B) MFCs on aligned nanofibrous scaffold, and (C) MFCs on silicone membrane. $\left[\mathrm{Ca}^{2+}\right]_{\mathrm{i}}$ was detected fluorescently using Cal-520 ${ }^{\mathrm{TM}}$ AM. Scale bar $=200 \mu \mathrm{m}$. (D) Cell area $\left(\mu \mathrm{m}^{2}\right),(\mathbf{E})$ cell aspect ratio, and (F) circularity. (\#), $p<0.05$ compared to native; $(\mathrm{x}), p<0.05$ compared to scaffold. Data in $(\mathbf{D}),(\mathbf{E})$, and $(\mathbf{F})$ are presented as mean \pm standard deviation.
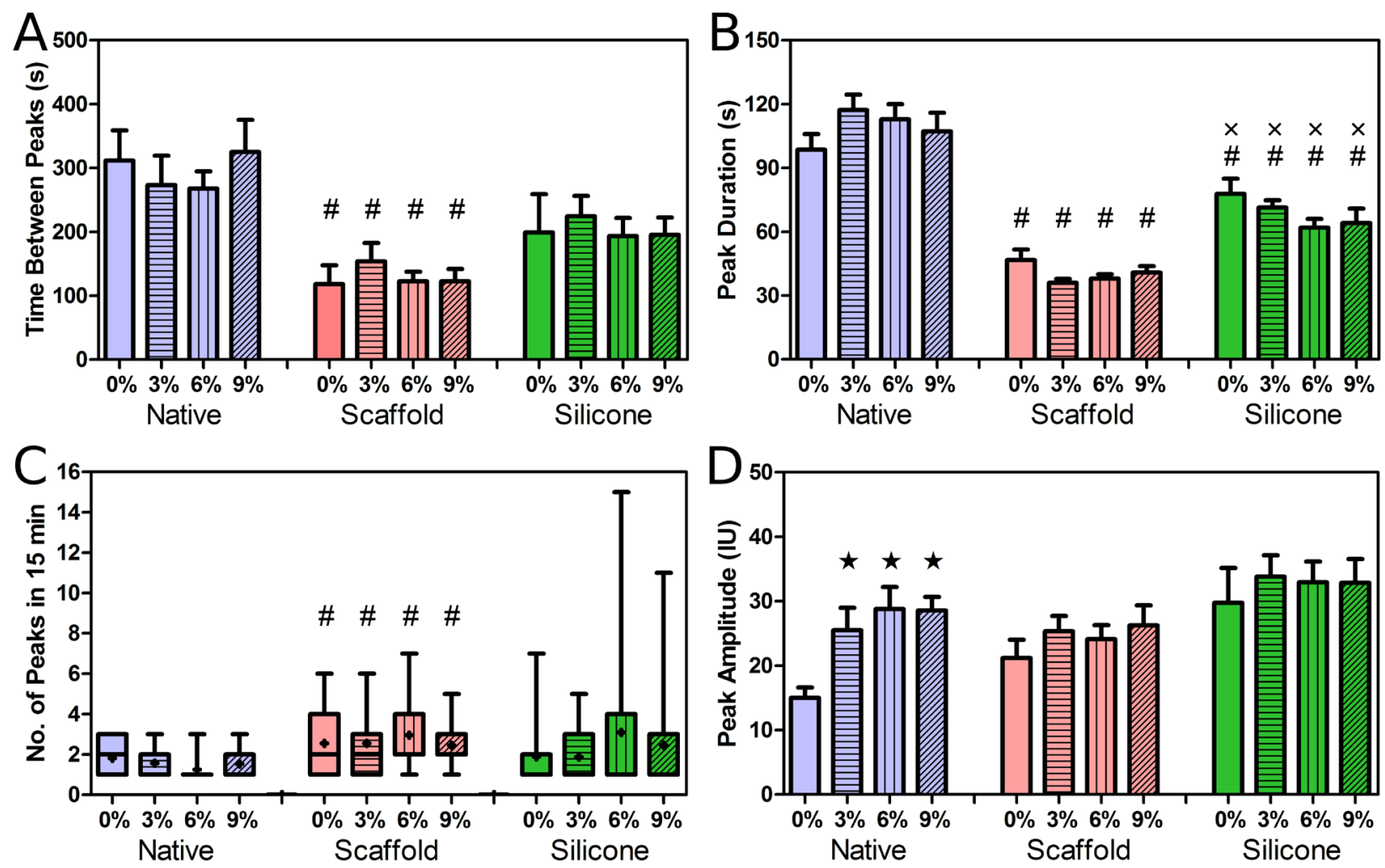

Fig. 4. (A) Time between oscillation peaks (sec), (B) peak duration (sec), (C) number of peaks in 15 min, and (D) peak amplitude for MFCs in the native meniscus, on aligned scaffolds, and on silicone membranes. (\#), $p<0.05$ compared to strain-matched native; $(\mathrm{x}), p<0.05$ compared to strain-matched scaffold; $(\star), p<0.05$ compared to $0 \%$ native. Data in $(\mathbf{C})$ are presented as a box and whisker plot showing the minimum, lower quartile, median, upper quartile, and maximum values, with $(\bullet)$ showing the mean. All other data shown as the mean \pm standard error. 

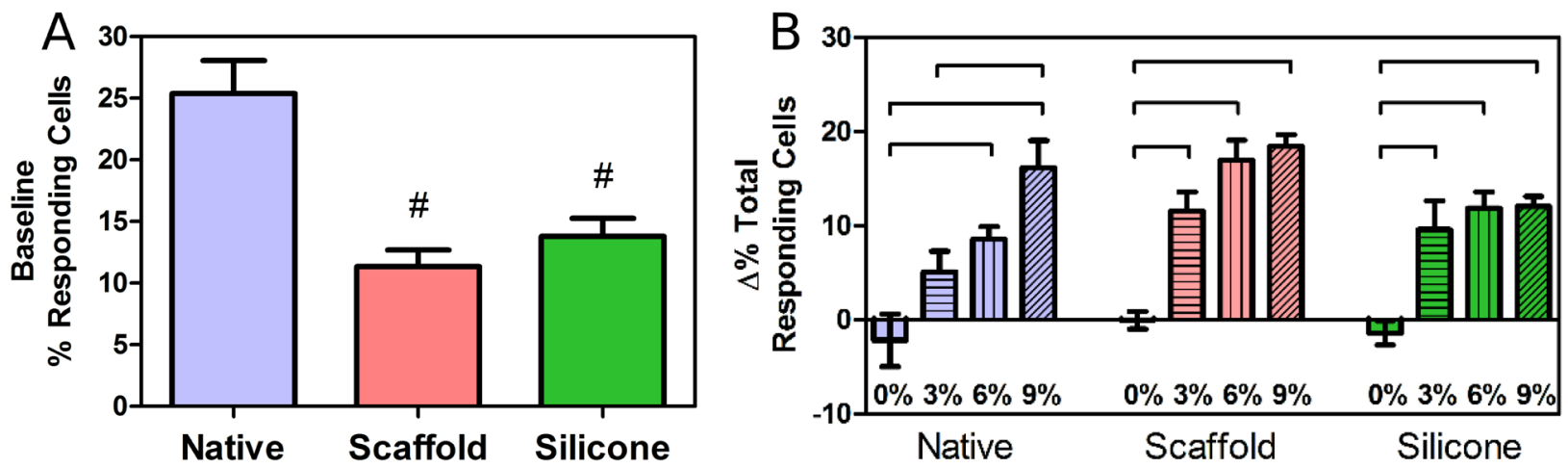

Fig. 5. (A) Percentage of cells with spontaneous $\left[\mathrm{Ca}^{2+}\right]_{i}$ oscillations during baseline measurement in native tissue, on aligned scaffold, and on silicone membranes. (B) Change from baseline in percentage of responding cells in native, aligned scaffold, and silicone membrane groups with the application of tensile strain (\%). (\#), $p<0.05$ compared to native. Bars, $p<0.05$.

Fig. 6. Change from baseline in percentage of responding cells in aligned scaffold and silicone membrane groups linearly increases with tensile strains below $3 \%$, but reaches a threshold in responsivity at strains over $6 \%$.

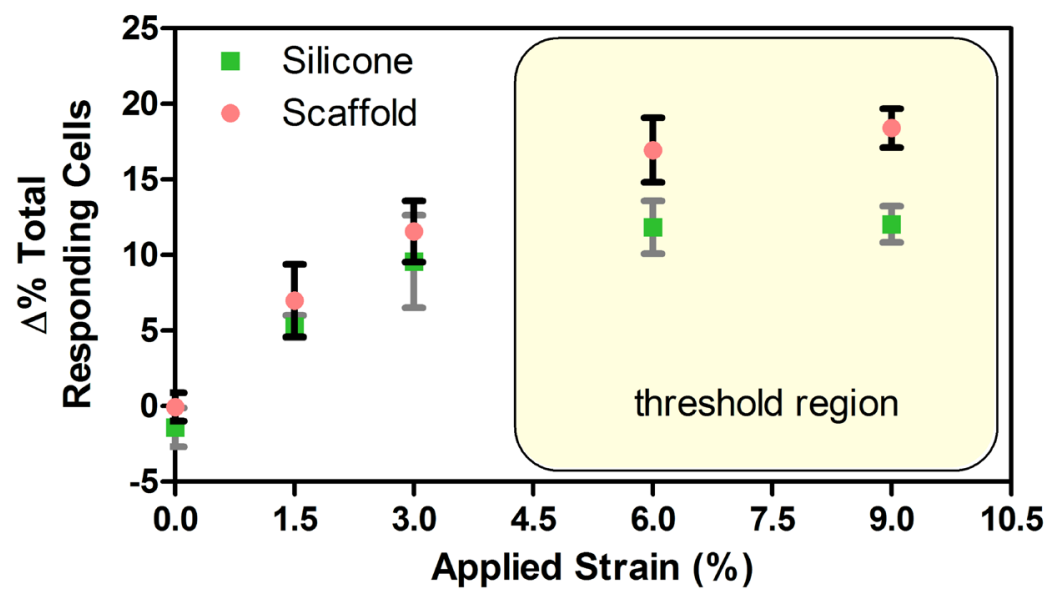

\section{Results}

\section{Cellular alignment, morphology, and baseline}

\section{$\left[\mathrm{Ca}^{2+}\right]$ signalling}

Cells within the native meniscus, on scaffold, and in the silicone group all showed a baseline level of calcium activity, as evidenced by regular oscillations in $\left[\mathrm{Ca}^{2+}\right]_{i}$ over the 15 min observation period before the application of tensile deformation. Figs. 2A and B illustrate the representative $\left[\mathrm{Ca}^{2+}\right]_{\mathrm{i}}$ oscillations occurring in cells in the native meniscus samples.

Cells within native meniscus tissue and on nanofibrous scaffolds were aligned in the direction of collagen or PCL fibres (Figs. 3A and B). No prevailing cell alignment was observed in the silicone membrane group (Fig. 3C). Cell area for the silicone membrane group was significantly greater compared to both native and scaffold groups, and cell area in the scaffold group was larger than the native group ( $p<0.05$; Fig. 3D). Cell aspect ratio, a measure of cell elongation, was greatest in the scaffold group and lowest in the silicone membrane group $(p<0.05$; Fig. 3E). Similarly, circularity was the greatest in the silicone membrane group and lowest in the scaffold group $(p<0.05$; Fig. 3F).

\section{Effect of cellular microenvironment on $\left[\mathrm{Ca}^{2+}\right]_{\mathrm{i}}$ response}

The cellular microenvironment had a profound effect on the temporal characteristics of $\left[\mathrm{Ca}^{2+}\right]_{\mathrm{i}}$ signalling in meniscus cells, independent of applied strain magnitude. These differences were apparent in the time between peaks, peak duration, and number of peaks each cell produced during a 15 min period. In the native tissue group, cells exhibited $\left[\mathrm{Ca}^{2+}\right]_{\mathrm{i}}$ oscillations every $200-400 \mathrm{~s}$ on average (Fig. 4A). Cells on aligned scaffolds had significantly more frequent oscillations compared to strain-matched native tissue groups ( $p<0.05$; Fig. $4 \mathrm{~A}$ ). While the mean time between peaks of the silicone membrane group was less than that of the native and higher than that of the scaffold groups, no statistical difference was observed.

Average oscillation duration in the native tissue group was approximately $100 \mathrm{~s}$ (Fig. 4B). $\left[\mathrm{Ca}^{2+}\right]_{\mathrm{i}}$ oscillation duration in the aligned scaffold group was significantly shorter compared to the native tissue group, lasting $\sim 30$ $50 \mathrm{~s}(p<0.05$; Fig. 4B). Oscillation duration in the silicone membrane group was significantly shorter than the native tissue group $(p<0.05)$, but longer than the aligned scaffold group ( $p<0.05$ ), lasting between 60-80 s (Fig. 4B). 
The number of $\left[\mathrm{Ca}^{2+}\right]_{\mathrm{i}}$ peaks in meniscus cells during the 15 min observation period was generally more variable in the aligned scaffold (1-7 oscillations) and silicone membrane (1-15 oscillations) groups compared to the native tissue group (1-3 oscillations; Fig. 4C). While cells on aligned scaffolds showed more oscillations compared to the native tissue group $(p<0.05)$, no differences were observed between the silicone membrane group and native tissue or aligned scaffold groups, given the large variation in this measurement (Fig. 4C).

\section{Effect of strain on $\left[\mathrm{Ca}^{2+}\right]_{\mathrm{i}}$ response}

Oscillation peak $\left[\mathrm{Ca}^{2+}\right]_{\mathrm{i}}$ amplitude significantly increased with strain compared to $0 \%$ in the native tissue group ( $p<0.05$; Fig. 4D). In contrast, no change in peak amplitude was observed in either the aligned scaffold or silicone membrane groups with increasing strain (Fig. 4D). Furthermore, no changes were observed in time between peaks, peak duration, and number of peaks for all groups with strain (Figs. 4A-C).

Application of uniaxial tensile strain had a marked impact on the population response of meniscus cells, increasing the fraction of the population showing $\left[\mathrm{Ca}^{2+}\right]_{i}$ oscillations. Under baseline conditions (no strain), cells in native meniscus tissue, on aligned scaffold, and on silicone membrane showed spontaneous $\left[\mathrm{Ca}^{2+}\right]_{i}$ oscillations (Fig. $5 \mathrm{~A})$. At this baseline, significantly more cells showed oscillations in the native tissue group (25\%) compared to both aligned scaffold and silicone membrane groups (10-15\%; $p<0.05$; Fig. 5A). With strain application, the percentage of responding cell increased linearly in the native tissue group, where significantly more cells responded at 6 and $9 \%$ strain compared to $0 \%$, and at $9 \%$ strain compared to $3 \%(p<0.05$; Fig. $5 \mathrm{~B})$. The percentage of responding cells also increased with strain in both aligned scaffold and silicone membrane groups, however, these groups showed a "step-like" response to strain, where significantly more cells responded with $3 \%$ strain compared to $0 \%(p<0.05)$, but this increase in responsiveness plateaued at $6-9 \%$ (Fig. 5B). In order to determine whether the change in responding cells increases linearly at a lower strain range (i.e. $<3 \%$ strain), we further investigated the effect of $1.5 \%$ strain increments on the change in responding cells in these two groups. Under a lower range of applied strain $(<3 \%)$, the percentages of responding cells increased linearly in both the aligned scaffold and silicone membrane groups (Fig. 6).

\section{Discussion}

The objective of this study was to investigate the effect of cellular microenvironment and tensile deformation on $\left[\mathrm{Ca}^{2+}\right]_{\mathrm{i}}$ response in MFCs. Findings from this work showed that $\left[\mathrm{Ca}^{2+}\right]_{\mathrm{i}}$ regulation by cells within the native meniscus tissue microenvironment was considerably different from $\left[\mathrm{Ca}^{2+}\right]_{\mathrm{i}}$ regulation by MFCs on either aligned nanofibrous scaffolds or flat silicone membranes. Our results further suggest that increasing levels of tensile strain recruit a larger fraction of the total cell population to response, both in situ and in vitro, with a higher baseline level of responding cells in native tissue. These findings have significant implications for mechanobiology of load-bearing fibrous tissues that are prone to injury and degeneration. Often times, mechanically-induced $\left[\mathrm{Ca}^{2+}\right]_{\mathrm{i}}$ signalling investigations utilise simplified systems where isolated cells are seeded onto a biocompatible substrate (Arnoczky et al., 2002a; Chen et al., 2000; Godbout et al., 2013; Hutcheson et al., 2012; Jing et al., 2013; Kim et al., 2009; Lu et al., 2012; Mizuno, 2005; Pritchard et al., 2002; Pritchard and Guilak, 2004), and therefore, do not provide information on how cells in situ respond to mechanical cues in the context of the native microenvironment in healthy and/or pathologic tissues. The current study highlights differences in cell signalling between in situ and in vitro microenvironments. From a tissue engineering perspective, the current findings also serve to establish cellular benchmarks for maturing engineered constructs, where native tissue-like calcium regulation may be an important outcome by which to judge engineered tissue functional parity with native tissue.

An interesting finding in this work was that tensile strain had minimal to no effect on the characteristics of $\left[\mathrm{Ca}^{2+}\right]_{\mathrm{i}}$ oscillations, including their frequency, duration, and number, with the principal outcome of strain application being the recruitment of a greater fraction of cells into this oscillatory state. However, the $\left[\mathrm{Ca}^{2+}\right]_{\mathrm{i}}$ oscillation parameters did vary markedly between experimental groups (Figs. 4A-C), suggesting that the cellular microenvironment has a strong influence on establishing the baseline $\left[\mathrm{Ca}^{2+}\right]_{\mathrm{i}}$ oscillation characteristics. In particular, the current study revealed that the peak duration and time between peaks was significantly shorter, and therefore peaks were more rapid and frequent, in the aligned scaffold group compared to the native tissue group (Figs. 4A and B). The observed difference in the frequency of $\left[\mathrm{Ca}^{2+}\right]_{\mathrm{i}}$ oscillations might be due to the differences in substrate (matrix) stiffness and cell attachment (Degala et al., 2011; Godbout et al., 2013; Kim et al., 2009). For instance, $\left[\mathrm{Ca}^{2+}\right]_{\mathrm{i}}$ oscillation frequencies of myofibroblasts in collagen gel have been shown to escalate with increasing substrate elastic moduli, but become highly sporadic after a threshold stiffness of about $1.2 \mathrm{kPa}$ (Godbout et al., 2013). Furthermore, the frequency of $\left[\mathrm{Ca}^{2+}\right]_{i}$ oscillation in human mesenchymal stem cells also increases with increasing moduli of polyacrylamide gel substrates, and is regulated by the RhoA/ROCK signalling pathway (Kim et al., 2009). Indeed, substrate stiffness can intricately interact with cell shapes (e.g., area; Fig. 3D), ultimately affecting cell mechanics and activities (Tee et al., 2011), suggesting strong influence of cell-matrix interactions on $\left[\mathrm{Ca}^{2+}\right]_{\mathrm{i}}$ signalling.

Interestingly, $\left[\mathrm{Ca}^{2+}\right]_{\mathrm{i}}$ oscillation characteristics of the silicone group were also different compared to both native tissue and aligned scaffold groups, where duration and time between peaks were shorter than the native tissue group, but longer than the aligned scaffold group (Figs. $4 \mathrm{~A}$ and $\mathrm{B})$. Here, in addition to the effect of substrate stiffness, cell alignment (random for silicone membrane $v s$. aligned for scaffold and native groups; Figs. 3E and F) could have played a role in the observed differences in oscillation parameters, indicating the importance of 
substrate surface morphology and cell shape on calcium signalling. For example, it has been shown that an elongated mesenchymal stem cell morphology dictated by an aligned nanofibrous topography can drive increased synthesis of fibrous markers compared to cells of rounder shape (Baker et al., 2010). The direction of stretch with respect to the direction of cell alignment has also been shown to alter gene expression profiles (Kurpinski et al., 2006), though the impact of cellular anisotropy on $\left[\mathrm{Ca}^{2+}\right]_{\mathrm{i}}$ signalling remains to be investigated.

At baseline, more cells were spontaneously responding in native tissue, compared to both scaffold and silicone groups (Fig. 5A). One possible explanation is the presence of endogenous soluble molecules, such as ATP or cytokines in the native ECM (Elfervig et al., 2001; Pritchard and Guilak, 2006; Yellowley et al., 1999). For instance, ATP alone is capable of triggering $\left[\mathrm{Ca}^{2+}\right]_{\mathrm{i}}$ modulation via purinergic pathways (Bodin and Burnstock, 2001). Indeed, the role of ATP in activating $\mathrm{P} 2$ purinergic receptors, and thus resulting in release of $\mathrm{Ca}^{2+}$ from intracellular stores (endoplasmic reticulum) and influx of $\mathrm{Ca}^{2+}$ from the ECM, has been demonstrated in chondrocytes (Elfervig et al., 2001; Pingguan-Murphy et al., 2006; Yellowley et al., 1999). Our findings suggest that the local biochemical environment might influence "baseline" cellular activity when direct mechanical signals are absent in load-bearing fibrous tissues.

While strain had minimal to no effect on the timing or duration of $\left[\mathrm{Ca}^{2+}\right]_{\mathrm{i}}$ oscillations, it did have a marked impact on the percentage of the cellular population showing $\left[\mathrm{Ca}^{2+}\right]_{i}$ oscillations. With application of uniaxial tensile strain, a greater percentage of cells responded in all groups. However, while the percent of responding cells in the native tissue increased linearly, the percent of responding cells on aligned scaffold and silicone membrane groups showed a "step-like" increase at $3 \%$ strain, with no further increases at either 6 or $9 \%$ strain (Fig. 5B). One explanation for this observation is that the local matrix strain at the cellular level is different between in situ native tissue and in vitro scaffold and silicone microenvironments. Indeed, previous studies have shown that the tissue-level strain becomes significantly more attenuated at the local matrix or cellular level in native fibrous tissues, such as tendon (Cheng and Screen, 2007; Han et al., 2013; Screen et al., 2004), meniscus (Han et al., 2013; Upton et al., 2008), and annulus fibrosus (Bruehlmann et al., 2004a; Han et al., 2013), compared to aligned PCL nanofibrous scaffolds, where the strain transfer is direct and uniform (Han et al., 2013). This suggests that cells in the native tissue experience much less strain than the applied strain, and thereby can recruit more cells to respond before reaching a maximal activation state. On the contrary, the more direct strain transfer to the cells on aligned scaffolds and silicone membranes may have resulted in reaching a "threshold" strain evoking the maximal number of responding cells. This is further supported by the fact that the percentages of responding cells increased linearly in both aligned scaffold and silicone membrane groups within the strain range of $0-3 \%$ (Fig. 6).
It is also important to note that not all cells responded to strain, where the percentage of responding cells was $\sim 25-45 \%$, depending on the group (Figs. 5 and 6). This is consistent with previous observations on chondrocytes seeded in agarose hydrogels and subjected to compressive loading (Pingguan-Murphy et al., 2005; PingguanMurphy et al., 2006; Roberts et al., 2001). MFCs from the outer meniscus may consist of heterogeneous cell subpopulations, with some whose mechano-response is based on calcium signalling. For example, it has been shown that the outer meniscus contains both elongated fibroblastlike and rounded chondrocyte-like cells in fibrous and proteoglycan-rich regions, respectively, suggesting the presence of heterogeneous cell sub-populations within a region of native tissues (Han et al., 2013). Alternatively, the non-responding cells may have been at a different phase of cell-cycle cycle, particularly in the in vitro culture systems (Pingguan-Murphy et al., 2005).

Differences in calcium signalling between the native tissue and cells cultured in the in vitro systems employed in the current study also may be influenced by phenotypic alterations that primary cells undergo during isolation and culture expansion. Indeed, such differences further highlight the importance of establishing cellular benchmarks for maturing engineered constructs. In such constructs, as cells regain their original phenotype and deposit appropriate extracellular matrix proteins with increasing culture period under appropriate differentiation conditions, calcium signalling would be expected to return toward native tissue benchmarks. For instance, subjecting the cell-seeded PCL constructs to a long-term culture instructs the cells to deposit a significant amount of organised collagen and proteoglycan with time (Baker et al., 2011; Nerurkar et al., 2009; Nerurkar et al., 2011). However, whether the cells in such constructs exhibit similar $\left[\mathrm{Ca}^{2+}\right]_{\mathrm{i}}$ oscillation characteristics compared to the native tissue remains to be determined.

The differences in calcium response (i.e., number of responding cells, peak duration, time between peaks and number of peaks) observed in the current study may have important implications for cell function. For example, stimulating chondrocyte TRPV4 channels significantly increases the percentage of cells responding, the number of $\left[\mathrm{Ca}^{2+}\right]_{i}$ oscillations, and therefore frequency, which results in enhanced anabolic gene expression and matrix synthesis that are required to produce a functional cartilage (O'Conor et al., 2014). Similarly, blocking TRPV4 channels reduced anabolic gene expression and matrix synthesis, confirming the role of $\left[\mathrm{Ca}^{2+}\right]_{i}$ modulation in critical cell activities for tissue engineering ( $\mathrm{O}^{\prime} \mathrm{Conor}$ et al., 2014). In addition, it has been established that the cells utilise different $\left[\mathrm{Ca}^{2+}\right]_{i}$ modulation mechanisms (i.e. $\mathrm{Ca}^{2+}$ entry and exit mechanisms) to shape $\mathrm{Ca}^{2+}$ signals in time and amplitude, which ultimately has both short and long-term consequences on cellular activities (Bootman et al., 2001). Therefore, future studies investigating the link between mechanical perturbation, $\left[\mathrm{Ca}^{2+}\right]_{\mathrm{i}}$ modulation, and specific cell activities will be critical for designing a functional tissue engineered construct. 


\section{Conclusion}

In this study, we developed a system capable of simultaneously stretching and imaging $\left[\mathrm{Ca}^{2+}\right]_{\mathrm{i}}$ oscillations in fibrous tissue cells, both in situ and in vitro. Using this device, we confirmed the hypothesis that $\left[\mathrm{Ca}^{2+}\right]_{\mathrm{i}}$ response in MFCs is dependent on cellular microenvironment and tensile deformation. Specifically, the outcomes demonstrate that temporal characteristics are influenced primarily by microenvironment while strain recruits additional cells to a phenotypic status typified by regular oscillations in intracellular calcium. Findings from this study will be important for understanding mechanobiology of fibrous tissues during development, growth, maintenance and repair, and will establish new biological/cellular benchmarks of mechano-responsivity for functional tissue engineering.

\section{Acknowledgements}

The authors would like to thank Lachlan Smith, Ph.D., Lucas Lu, Ph.D., and Miri Park for helpful discussions. Research was funded by The National Institutes of Health grant No. R01EB002425. We wish to confirm that there are no known conflicts of interest associated with this publication and there has been no significant financial support for this work that could have influenced its outcome.

\section{References}

Arnoczky SP, Tian T, Lavagnino M, Gardner K, Schuler P, Morse P (2002a) Activation of stress-activated protein kinases (SAPK) in tendon cells following cyclic strain: the effects of strain frequency, strain magnitude, and cytosolic calcium. J Orthop Res 20: 947-952.

Arnoczky SP, Lavagnino M, Whallon JH, Hoonjan A (2002b) In situ cell nucleus deformation in tendons under tensile load; a morphological analysis using confocal laser microscopy. J Orthop. Res 20: 29-35.

Baker BM, Mauck RL (2007) The effect of nanofiber alignment on the maturation of engineered meniscus constructs. Biomaterials 28: 1967-1977.

Baker BM, Gee AO, Metter RB, Nathan AS, Marklein RA, Burdick JA, Mauck RL (2008) The potential to improve cell infiltration in composite fiber-aligned electrospun scaffolds by the selective removal of sacrificial fibers. Biomaterials 29: 2348-2358.

Baker BM, Nathan AS, Huffman GR, Mauck RL (2009a) Tissue engineering with meniscus cells derived from surgical debris. Osteoarthritis Cartilage 17: 336-345.

Baker BM, Nerurkar NL, Burdick JA, Elliott DM, Mauck RL (2009b) Fabrication and modeling of dynamic multipolymer nanofibrous scaffolds. J Biomech Eng 131: 101012

Baker BM, Nathan AS, Gee AO, Mauck RL (2010) The influence of an aligned nanofibrous topography on human mesenchymal stem cell fibrochondrogenesis. Biomaterials 31: 6190-6200.

Baker BM, Shah RP, Huang AH, Mauck RL (2011) Dynamic tensile loading improves the functional properties of mesenchymal stem cell-laden nanofiber-based fibrocartilage. Tissue Eng Part A 17: 1445-1455.

Baker BM, Shah RP, Silverstein AM, Esterhai JL, Burdick JA, Mauck RL (2012) Sacrificial nanofibrous composites provide instruction without impediment and enable functional tissue formation. Proc Natl Acad Sci USA 109: 14176-14181.

Berridge MJ, Bootman MD, Roderick HL (2003) Calcium signalling: dynamics, homeostasis and remodelling. Nat Rev Mol Cell Biol 4: 517-529.

Bodin P, Burnstock G (2001) Purinergic signalling: ATP release. Neurochem Res 26: 959-969.

Bootman MD, Lipp P, Berridge MJ (2001) The organisation and functions of local $\mathrm{Ca}(2+)$ signals. J Cell Sci 114: 2213-2222.

Bruehlmann SB, Hulme PA, Duncan NA (2004a) In situ intercellular mechanics of the bovine outer annulus fibrosus subjected to biaxial strains. J Biomech 37: 223-231.

Bruehlmann SB, Matyas JR, Duncan NA (2004b) Collagen fibril sliding governs cell mechanics in the annulus fibrosus: an in situ confocal microscopy study of bovine discs. Spine 29: 2612-2620.

Campbell JJ, Bader DL, Lee DA (2008) Mechanical loading modulates intracellular calcium signaling in human mesenchymal stem cells. J Appl Biomater Biomech 6: 9-15.

Chen NX, Ryder KD, Pavalko FM, Turner CH, Burr DB, Qiu J, Duncan RL (2000) Ca2+ regulates fluid shearinduced cytoskeletal reorganization and gene expression in osteoblasts. Am J Physiol Cell Physiol 278: C989-C997.

Chen NX, Geist DJ, Genetos DC, Pavalko FM, Duncan RL (2003) Fluid shear-induced NFkappaB translocation in osteoblasts is mediated by intracellular calcium release. Bone 33: 399-410.

Cheng VWT, Screen HRC (2007) The micro-structural strain response of tendon. J Mater Sci 42: 8957-8965.

Degala S, Zipfel WR, Bonassar LJ (2011) Chondrocyte calcium signaling in response to fluid flow is regulated by matrix adhesion in 3-D alginate scaffolds. Arch Biochem Biophys 505: 112-117.

Duncan NA, Bruehlmann SB, Hunter CJ, Shao X, Kelly EJ (2014) In situ cell-matrix mechanics in tendon fascicles and seeded collagen gels: implications for the multiscale design of biomaterials. Comput Methods Biomech Biomed Eng 17: 39-47.

Elfervig MK, Graff RD, Lee GM, Kelley SS, Sood A, Banes AJ (2001) ATP induces $\mathrm{Ca}(2+)$ signaling in human chondrons cultured in three-dimensional agarose films. Osteoarthritis Cartilage 9: 518-526.

Fitzgerald JB, Jin M, Dean D, Wood DJ, Zheng MH, Grodzinsky AJ (2004) Mechanical compression of cartilage explants induces multiple time-dependent gene expression patterns and involves intracellular calcium and cyclic AMP. J Biol Chem 279: 19502-19511.

Godbout C, Follonier Castella L, Smith EA, Talele N, Chow ML, Garonna A, Hinz B (2013) The mechanical 
environment modulates intracellular calcium oscillation activities of myofibroblasts. PLoS One 8: e64560.

Guerin HAL, Elliott DM (2006) Degeneration affects the fiber reorientation of human annulus fibrosus under tensile load. J Biomech 39: 1410-1418.

Han S-K, Wouters W, Clark A, Herzog W (2012) Mechanically induced calcium signaling in chondrocytes in situ. J Orthop Res 30: 475-481.

Han WM, Heo S-J, Driscoll TP, Smith LJ, Mauck RL, Elliott DM (2013) Macro- to microscale strain transfer in fibrous tissues is heterogeneous and tissue-specific. Biophys J 105: 807-817.

Heo S-J, Nerurkar NL, Baker BM, Shin J-W, Elliott DM, Mauck RL (2011) Fiber stretch and reorientation modulates mesenchymal stem cell morphology and fibrous gene expression on oriented nanofibrous microenvironments. Ann Biomed Eng 39: 2780-2790.

Hutcheson JD, Venkataraman R, Baudenbacher FJ, Merryman WD (2012) Intracellular $\mathrm{Ca}(2+)$ accumulation is strain-dependent and correlates with apoptosis in aortic valve fibroblasts. J Biomech 45: 888-894.

Ishihara Y, Sugawara Y, Kamioka H, Kawanabe N, Kurosaka H, Naruse K, Yamashiro T (2012) In situ imaging of the autonomous intracellular $\mathrm{Ca}(2+)$ oscillations of osteoblasts and osteocytes in bone. Bone 50: 842-852.

Jing D, Lu XL, Luo E, Sajda P, Leong PL, Guo XE (2013) Spatiotemporal properties of intracellular calcium signaling in osteocytic and osteoblastic cell networks under fluid flow. Bone 53: 531-540.

Killian ML, Cavinatto L, Galatz LM, Thomopoulos S (2012) The role of mechanobiology in tendon healing. J Shoulder Elbow Surg 21: 228-237.

Kim T-J, Seong J, Ouyang M, Sun J, Lu S, Hong JP, Wang N, Wang Y (2009) Substrate rigidity regulates Ca2+ oscillation via RhoA pathway in stem cells. J Cell Physiol 218: $285-293$.

Kurpinski K, Chu J, Hashi C, Li S (2006) Anisotropic mechanosensing by mesenchymal stem cells. Proc Natl Acad Sci USA 103: 16095-16100.

Lake SP, Miller KS, Elliott DM, Soslowsky LJ (2009) Effect of fiber distribution and realignment on the nonlinear and inhomogeneous mechanical properties of human supraspinatus tendon under longitudinal tensile loading. J Orthop Res 27: 1596-1602.

Lee DA, Bader DL (1997) Compressive strains at physiological frequencies influence the metabolism of chondrocytes seeded in agarose. J Orthop Res 15: 181-188.

Lu XL, Huo B, Park M, Guo XE (2012) Calcium response in osteocytic networks under steady and oscillatory fluid flow. Bone 51: 466-473.

Mammoto A, Mammoto T, Ingber DE (2012) Mechanosensitive mechanisms in transcriptional regulation. J Cell Sci 125: 3061-3073.

Mauck RL, Martinez-Diaz GJ, Yuan X, Tuan RS (2007) Regional multilineage differentiation potential of meniscal fibrochondrocytes: implications for meniscus repair. Anat Rec 290: 48-58.

Mauck RL, Baker BM, Nerurkar NL, Burdick JA, Li W-J, Tuan RS, Elliott DM (2009) Engineering on the straight and narrow: the mechanics of nanofibrous assemblies for fiber-reinforced tissue regeneration. Tissue Eng Part B Rev 15: 171-193.

Melrose J, Ghosh P, Taylor TK (2001) A comparative analysis of the differential spatial and temporal distributions of the large (aggrecan, versican) and small (decorin, biglycan, fibromodulin) proteoglycans of the intervertebral disc. J Anat 198: 3-15.

Mizuno S (2005) A novel method for assessing effects of hydrostatic fluid pressure on intracellular calcium: a study with bovine articular chondrocytes. Am J Physiol Cell Physiol 288: C329-337.

Nathan AS, Baker BM, Nerurkar NL, Mauck RL (2011) Mechano-topographic modulation of stem cell nuclear shape on nanofibrous scaffolds. Acta Biomater 7: 57-66.

Nerurkar NL, Baker BM, Sen S, Wible EE, Elliott DM, Mauck RL (2009) Nanofibrous biologic laminates replicate the form and function of the annulus fibrosus. Nat Mater 8: 986-992.

Nerurkar NL, Han W, Mauck RL, Elliott DM (2011) Homologous structure-function relationships between native fibrocartilage and tissue engineered from MSCseeded nanofibrous scaffolds. Biomaterials 32: 461-468.

O'Conor CJ, Leddy HA, Benefield HC, Liedtke WB, Guilak F (2014) TRPV4-mediated mechanotransduction regulates the metabolic response of chondrocytes to dynamic loading. Proc Natl Acad Sci USA 111: 1316-1321.

Pingguan-Murphy B, Lee DA, Bader DL, Knight MM (2005) Activation of chondrocytes calcium signalling by dynamic compression is independent of number of cycles. Arch Biochem Biophys 444: 45-51.

Pingguan-Murphy B, El-Azzeh M, Bader DL, Knight MM (2006) Cyclic compression of chondrocytes modulates a purinergic calcium signalling pathway in a strain rate- and frequency-dependent manner. J Cell Physiol 209: 389-397.

Plaas A, Sandy JD, Liu H, Diaz MA, Schenkman D, Magnus RP, Bolam-Bretl C, Kopesky PW, Wang VM, Galante JO (2011) Biochemical identification and immunolocalizaton of aggrecan, ADAMTS5 and interalpha-trypsin-inhibitor in equine degenerative suspensory ligament desmitis. J Orthop Res 29: 900-906.

Pritchard S, Guilak F (2004) The role of F-actin in hypo-osmotically induced cell volume change and calcium signaling in anulus fibrosus cells. Ann Biomed Eng 32: 103-111.

Pritchard S, Guilak F (2006) Effects of interleukin-1 on calcium signaling and the increase of filamentous actin in isolated and in situ articular chondrocytes. Arthritis Rheum. 54: 2164-2174.

Pritchard S, Erickson GR, Guilak F (2002) Hyperosmotically induced volume change and calcium signaling in intervertebral disk cells: the role of the actin cytoskeleton. Biophys J 83: 2502-2510.

Roberts SR, Knight MM, Lee DA, Bader DL (2001) Mechanical compression influences intracellular $\mathrm{Ca} 2+$ signaling in chondrocytes seeded in agarose constructs. J Appl Physiol 90: 1385-1391.

Screen HRC, Lee DA, Bader DL, Shelton JC (2004) An investigation into the effects of the hierarchical structure of tendon fascicles on micromechanical properties. Proc Inst Mech Eng H 218: 109-119. 
Stella JA, Liao J, Hong Y, David Merryman W, Wagner WR, Sacks MS (2008) Tissue-to-cellular level deformation coupling in cell micro-integrated elastomeric scaffolds. Biomaterials 29: 3228-3236.

Sun Y, Mauerhan DR, Kneisl JS, James Norton H, Zinchenko N, Ingram J, Hanley EN Jr, Gruber HE (2012) Histological examination of collagen and proteoglycan changes in osteoarthritic menisci. Open Rheumatol J 6: 24-32.

Szczesny S, Elliott D (2014) Interfibrillar shear stress is the loading mechanism of collagen fibrils in tendon. Acta Biomater 10: 2582-2590.

Tanaka N, Ohno S, Honda K, Tanimoto K, Doi T, Ohno-Nakahara M, Tafolla E, Kapila S, Tanne K (2005) Cyclic mechanical strain regulates the PTHrP expression in cultured chondrocytes via activation of the $\mathrm{Ca} 2+$ channel. J Dent Res 84: 64-68.

Tee S-Y, Fu J, Chen CS, Janmey PA (2011) Cell shape and substrate rigidity both regulate cell stiffness. Biophys J 100: L25-27.

Upton ML, Gilchrist CL, Guilak F, Setton LA (2008) Transfer of macroscale tissue strain to microscale cell regions in the deformed meniscus. Biophys J 95: 21162124.

Vanderploeg EJ, Wilson CG, Imler SM, Ling CHY, Levenston ME (2012) Regional variations in the distribution and colocalization of extracellular matrix proteins in the juvenile bovine meniscus. J Anat 221: 174186.

Wang VM, Bell RM, Thakore R, Eyre DR, Galante JO, Li J, Sandy JD, Plaas A (2012) Murine tendon function is adversely affected by aggrecan accumulation due to the knockout of ADAMTS5. J Orthop Res 30: 620-626.

Wilson CG, Nishimuta JF, Levenston ME (2009) Chondrocytes and meniscal fibrochondrocytes differentially process aggrecan during de novo extracellular matrix assembly. Tissue Eng Part A 15: 1513-1522.
Yellowley CE, Jacobs CR, Donahue HJ (1999) Mechanisms contributing to fluid-flow-induced $\mathrm{Ca} 2+$ mobilization in articular chondrocytes. J Cell Physiol 180: 402-408.

\section{Discussion with Reviewer}

Reviewer II: In this paper, the substrates were coated with fibronectin. It is interesting to know the results if the substrates were coated with collagen. The meniscus contains collagen, fibronectin and thrombospondin. The composition of the microenvironment might also influence calcium response.

Authors: Thank you for this interesting question. It is true that other adhesion proteins such as thrombospondin and type VI collagen also exist in the meniscus (Miller and McDevitt, 1991), therefore, it would be interesting to know how the composition of the microenvironment influences the calcium response. It is possible (and perhaps likely) that there may be differences in the number of focal adhesions established by cells coupled to different matrix ligands, such as collagen. This could potentially alter the cell-matrix interaction and/or baseline contractility of cells, resulting in different cellular morphology and calcium response. However, further studies will be required to determine whether and how the adhesion protein composition of the microenvironment also influences calcium response.

\section{Additional Reference}

Miller RR, McDevitt CA (1991) Thrombospondin in ligament, meniscus and intervertebral disc. Biochim Biophys Acta 1115: 85-88. 